\title{
Glycaemic index, glycaemic load and risk of endometrial cancer: a prospective cohort study
}

\author{
Stephanie AN Silvera ${ }^{1, *}$, Thomas E Rohan ${ }^{1}$, Meera Jain ${ }^{2}$, Paul D Terry ${ }^{3}$, Geoffrey R Howe ${ }^{4}$ \\ and Anthony B Miller ${ }^{2}$ \\ 'Department of Epidemiology and Population Health, Albert Einstein College of Medicine, 1300 Morris Park \\ Avenue, Room 1301, Bronx, NY 10461, USA: ${ }^{2}$ Department of Public Health Sciences, University of Toronto, Toronto, \\ Canada: ${ }^{3}$ National Institute of Environmental Health Sciences, National Institutes of Health, Department of Health \\ and Human Sciences, Research Triangle Park, NC, USA: ${ }^{4}$ Department of Epidemiology, Mailman School of Public \\ Health, Columbia University, New York, NY, USA
}

\section{Submitted 9 December 2004: Accepted 24 March 2005}

\begin{abstract}
Objective: High-glycaemic-load diets may increase endometrial cancer risk by increasing circulating insulin levels and, as a consequence, circulating oestrogen levels. Given the paucity of epidemiological data regarding the relationship between dietary glycaemic index and glycaemic load and endometrial cancer risk, we sought to examine these associations using data from a prospective cohort study.

Design, setting and subjects: We examined the association between dietary glycaemic load and endometrial cancer risk in a cohort of 49613 Canadian women aged between 40 and 59 years at baseline who completed self-administered foodfrequency questionnaires between 1982 and 1985. Linkages to national mortality and cancer databases yielded data on deaths and cancer incidence, with follow-up ending between 1998 and 2000.

Results: During a mean of 16.4 years of follow-up, we observed 426 incident cases of endometrial cancer. Hazard ratios for the highest versus the lowest quartile level of overall glycaemic index and glycaemic load were 1.47 (95\% confidence interval $(\mathrm{CI})=0.90-2.41 ; \quad P$ for trend $=0.14)$ and $1.36(95 \% \quad \mathrm{CI}=1.01-1.84 ; \quad P$ for trend $=0.21$, respectively. No association was observed between total carbohydrate or total sugar consumption and endometrial cancer risk. Among obese women (body mass index $>30 \mathrm{~kg} \mathrm{~m}^{-2}$ ) the hazard ratio for the highest versus the lowest quartile level of glycaemic load was $1.88(95 \% \mathrm{CI}=1.08-3.29 ; P$ for trend $=0.54)$ and there was a $55 \%$ increased risk for the highest versus the lowest quartile level of glycaemic load among premenopausal women. There was also evidence to support a positive association between glycaemic load and endometrial cancer risk among postmenopausal women who had used hormone replacement therapy.

Conclusions: Our data suggest that diets with high glycaemic index or high glycaemic load may be associated with endometrial cancer risk overall, and particularly among obese women, premenopausal women and postmenopausal women who use hormone replacement therapy.
\end{abstract}

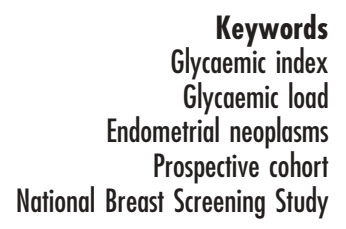

Keycords load Prospective cohort National Breast Screening Study
Glycaemic index is a means of classifying the carbohydrate content of individual foods according to their postprandial glycaemic effects and hence their effects on blood insulin levels ${ }^{1-3}$. Using glycaemic index values, the total glycaemic effect of the diet (glycaemic load) can be estimated $^{4}$. While high-glycaemic-index diets, characterised by higher intakes of foods rich in starch (such as white rice and potatoes) and simple sugars, have been associated with hyperinsulinaemia ${ }^{1,4,5}$, low-glycaemicindex foods (e.g. those high in fibre, such as whole grains and most fruits and vegetables) have been shown to be associated with a lower postprandial rise in insulin ${ }^{3}$, thus maintaining insulin sensitivity ${ }^{6}$. Higher circulating plasma insulin levels have been associated with lower sex hormone-binding globulin production ${ }^{7,8}$, leading to higher free oestrogen levels. Insulin also downregulates the synthesis of insulin-like growth factor binding protein-1, thereby increasing the activity of insulin-like growth factor- $\mathrm{I}^{9,10}$, which can result in an increase in bioavailable plasma oestrogen ${ }^{11}$. Furthermore, Kaaks et al. ${ }^{9}$ noted that insulin may stimulate gonadal and adrenal synthesis of androgens, which are direct precursors of oestrogen synthesis. Given that endometrial cancer is strongly related to endogenous oestrogen 
levels $^{9,12,13}$, it is conceivable that diets with high glycaemic index and high glycaemic load might be associated with an increased risk of endometrial cancer via modulation of insulin and thus circulating oestrogen levels ${ }^{12}$.

To date, there appear to have been only two studies of glycaemic load and glycaemic index in relation to endometrial cancer risk. One, a case-control study by Augustin et al. ${ }^{14}$, found a statistically significant increased risk of endometrial cancer associated with the highest versus the lowest quintile level of dietary glycaemic index overall, and among overweight (body mass index (BMI) $>25 \mathrm{~kg} \mathrm{~m}^{-2}$ ) women and those who had ever used hormone replacement therapy (HRT). The other study, a prospective study by Folsom et ll $^{15}$, did not find an association between dietary glycaemic index or glycaemic load and risk in the total cohort, but did find a statistically significant increased risk for the highest versus the lowest quintile level of glycaemic load among postmenopausal, non-diabetic women with $\mathrm{BMI}>30 \mathrm{~kg} \mathrm{~m}^{-2}$. Given the paucity of epidemiological data, in the present study we examined the relationship between dietary glycaemic index and glycaemic load, as well as total carbohydrate and total sugar consumption (included because of their strong association with postprandial insulin response ${ }^{16}$ ), and endometrial cancer risk in a prospective study of Canadian women.

\section{Methods}

\section{Study population}

The design of our study has been described in detail elsewhere $^{17}$. Briefly, between 1980 and 1985, a total of 89835 women aged 40-59 years were recruited from the general population into the Canadian National Breast Screening Study (NBSS), a randomised controlled trial of screening for breast cancer ${ }^{18}$.

\section{Questionnaires}

At recruitment into the cohort, information was obtained from participants on demographic characteristics, lifestyle factors, menstrual and reproductive history, and use of oral contraceptives and replacement oestrogens. Starting in 1982 (that is, after some participants had completed their scheduled visits to the screening centres), a selfadministered food-frequency questionnaire (FFQ) was distributed to all new attendees at all screening centres and to women returning to the screening centres for rescreening ${ }^{19}$. The FFQ sought information on usual portion size and frequency of consumption of 86 food items, and included photographs of various portion sizes to assist respondents with quantifying intake. A comparison between the self-administered questionnaire and a full interviewer-administered questionnaire, which has been subjected to both validity and reliability testing ${ }^{19}$ and used in a number of epidemiological studies ${ }^{20}$, revealed that the two methods gave estimates of intake of the major macronutrients and dietary fibre that were moderately to strongly correlated with each other (reported correlation coefficients ranged from 0.47 to 0.72$)^{19}$. A total of 49613 dietary questionnaires were returned and available for analysis.

\section{Calculation of overall glycaemic index and glycaemic load}

Data from the completed self-administered questionnaires were used to estimate overall glycaemic index and glycaemic load. Glycaemic index values of foods were obtained from published reports based on studies in North America $^{4}$. Overall glycaemic index was calculated by multiplying the carbohydrate content (in grams) of a given food item by the number of servings per day of that food item and its glycaemic index value, summing over all food items reported, and dividing by the total carbohydrate in the diet. Total dietary glycaemic load was calculated by multiplying the carbohydrate content of a given food item by the number of servings consumed per day and its glycaemic index value and summing the values for all food items reported. Each unit increase in glycaemic load represents the insulin response to the equivalent of 1 gram of glucose or carbohydrate from white bread (depending on the standard used) ${ }^{21}$. When the reported glycaemic index values for foods were observed to vary across studies $^{4}$, we used the mean of the reported values of glycaemic index for that food. The main foods contributing to glycaemic load in the cohort include white bread (sliced), rolls, muffins, potatoes (baked, boiled and mashed), French fries, cakes, cookies, rice, pasta, pizza, cold breakfast cereals, pies and tarts, cola, other soft drinks, citrus fruits and juices and other fruits, crisp snacks (such as potato chips or popcorn), candy, chocolate, peas, beans and lentils, hot breakfast cereals, dark and wholegrain breads, corn, root vegetables other than potatoes, jam, jelly and honey, sugar in tea or coffee, ice cream, and peanut butter ${ }^{22}$.

\section{Ascertainment of outcome}

Cases were women who were diagnosed during follow-up with incident endometrial cancer. Incident endometrial cancers and deaths from all causes were ascertained by means of computerised record linkages to the Canadian Cancer Database and to the National Mortality Database, respectively, both of which are maintained by Statistics Canada. The linkages to the databases yielded data on mortality and cancer incidence to 31 December 2000 for women in Ontario, 31 December 1998 for women in Quebec, and 31 December 1999 for women in other regions in Canada.

\section{Statistical analysis}

Of the 49613 women for whom dietary data were available, we excluded women with extreme energy intake values (at least three standard deviations (SD) 
above or below the mean value for $\log _{\mathrm{e}}$ energy intake) $(n=502)$; women with prevalent endometrial cancer at baseline $(n=61)$; and women who had undergone a hysterectomy ( $n=14659)$. These exclusions left 34391 women available for analysis, amongst whom there were 426 incident cases of endometrial cancer. Study participants were at risk from their date of enrolment until the date of diagnosis of their endometrial cancer, until the termination of follow-up, or death, whichever was earlier.

Cox proportional hazards models (using age as the time scale) were used to estimate hazard ratios (HR) and 95\% confidence intervals (CI) for the association between energy-adjusted quartile levels of glycaemic load and overall glycaemic index and endometrial cancer risk; energy adjustment was performed using the residual method $^{23}$. Multivariate models included the variables listed in the footnote of Table 2. To test for trend we fitted the median value of each quartile as successive integers in the risk models ${ }^{24}$. We examined the associations overall and within strata defined BMI (defined as weight (kg)/ square of height $\left(\mathrm{m}^{2}\right)$; weight and height were measured at baseline ${ }^{25}$ ), self-reported vigorous physical activity (defined as jogging, running, brisk walking, vigorous sport, bicycling, heavy housework, etc.) and use of HRT (ever vs. never) (Table 3). In addition, we examined the associations within strata defined by menopausal status (Table 3). Women who reported having regular menstrual periods within the past 12 months were classified as premenopausal. Women whose menstrual periods had ceased at least 12 months before enrolment into the study and those who had had a bilateral oophorectomy were considered postmenopausal $^{26}$. Tests for interaction were based on likelihood ratio tests comparing models with and without product terms representing the variables of interest. Each of the interactions examined in Table 3 was adjusted for the other three factors where appropriate (e.g. the interaction between glycaemic load and BMI was adjusted for physical activity, menopausal status and use of HRT, in addition to the variables listed in the footnote to Table 3) so that the various interactions that were examined were independent of each other. Use of the LIFETEST procedure in SAS ${ }^{\mathrm{TM}}$ showed that the proportional hazards assumption was met in this dataset. All analyses were performed using SAS version 8 (SAS Institute, Cary, NC, USA).

\section{Results}

The average duration of follow-up for cohort members was 16.4 years, corresponding to a total of 565286 personyears of follow-up for the cohort. The mean (SD) age at diagnosis for the cases was 59.6 (6.5) years. As shown in Table 1, endometrial cancer risk was positively associated with BMI and duration of HRT use (among postmenopausal women) and inversely associated with parity and duration of oral contraceptive use in age-adjusted models, whereas pack-years of smoking, alcohol consumption, participation in vigorous physical activity, energy intake, age at menarche and menopausal status were not associated with endometrial cancer risk.

For the cohort as a whole, the mean (SD) energyadjusted overall glycaemic index and glycaemic load were 79.4 (24.2) and 147.4 (34.8) $\mathrm{g} \mathrm{day}^{-1}$, respectively. There was an approximately two-fold variation in mean glycaemic load values between the lowest and highest quartile levels (data not shown). Compared with those with low glycaemic load values, women with high glycaemic load values had lower alcohol consumption, were less likely ever to have smoked, had a shorter mean duration of oral contraceptive use, were more likely to be postmenopausal at baseline, and were less likely to have

Table 1 Age-adjusted hazard ratios (HR) and 95\% confidence intervals $(\mathrm{Cl})$ for the association between baseline variables and endometrial cancer

\begin{tabular}{|c|c|c|c|}
\hline Variable & Cases & Person-years & $\mathrm{HR}(95 \% \mathrm{Cl})$ \\
\hline \multicolumn{4}{|c|}{ Body mass index $\left(\mathrm{kg} \mathrm{m}^{-2}\right)$} \\
\hline$<25$ & 197 & 362802 & 1.00 (referent) \\
\hline $25-29$ & 120 & 144431 & $1.42(1.13-1.78)$ \\
\hline$>30$ & 105 & 51895 & $3.40(2.68-4.33)^{*}$ \\
\hline \multicolumn{4}{|l|}{ Energy intake (kcal) } \\
\hline$<1637$ & 109 & 141524 & 1.00 (referent) \\
\hline $1638-1976$ & 112 & 141332 & $1.02(0.79-1.33)$ \\
\hline $1977-2394$ & 92 & 141492 & $0.84(0.64-1.11)$ \\
\hline$>2394$ & 113 & 140938 & $1.05(0.80-1.37)$ \\
\hline \multicolumn{4}{|c|}{ Pack-years of smoking } \\
\hline 0 & 228 & 292783 & 1.00 (referent) \\
\hline $1-9$ & 82 & 105398 & $1.02(0.79-1.32)$ \\
\hline $10-19$ & 46 & 61935 & $0.96(0.70-1.32)$ \\
\hline$>20$ & 69 & 100574 & $0.85(0.65-1.11)$ \\
\hline \multicolumn{4}{|c|}{ Alcohol consumption $\left(\mathrm{g} \mathrm{day}^{-1}\right)$} \\
\hline 0 & 111 & 141211 & 1.00 (referent) \\
\hline $1-2$ & 107 & 124265 & $1.13(0.86-1.48)$ \\
\hline $3-9$ & 95 & 143272 & $0.89(0.68-1.18)$ \\
\hline$>10$ & 113 & 156538 & $0.97(0.75-1.27)$ \\
\hline \multicolumn{4}{|c|}{ Vigorous physical activity } \\
\hline None & 154 & 199758 & 1.00 (referent) \\
\hline Any & 188 & 255208 & $0.99(0.80-1.23)$ \\
\hline \multicolumn{4}{|c|}{ Age at menarche (years) } \\
\hline$<12$ & 201 & 224152 & 1.00 (referent) \\
\hline$>12$ & 225 & 341133 & $0.73(0.60-0.88)$ \\
\hline \multicolumn{4}{|l|}{ Parity } \\
\hline Nulliparous & 92 & 90625 & 1.00 (referent) \\
\hline $1-2$ & 155 & 208583 & $0.75(0.58-0.98)$ \\
\hline $3-4$ & 150 & 213420 & $0.65(0.50-0.84)$ \\
\hline$>5$ & 29 & 52289 & $0.46(0.30-0.71)^{*}$ \\
\hline \multicolumn{4}{|c|}{ Duration of oral contraceptive use (months) } \\
\hline 0 & 210 & 220052 & 1.00 (referent) \\
\hline $1-11$ & 71 & 86014 & $1.07(0.79-1.44)$ \\
\hline $12-35$ & 54 & 77306 & $0.86(0.63-1.17)$ \\
\hline $36-95$ & 50 & 93089 & $0.73(0.56-0.97)$ \\
\hline$>95$ & 41 & 88823 & $0.56(0.40-0.79)^{*}$ \\
\hline \multicolumn{4}{|l|}{ Menopausal status } \\
\hline Premenopausal & 232 & 31731 & 1.00 (referent) \\
\hline Postmenopausal & 177 & 359963 & $0.92(0.73-1.17)$ \\
\hline \multicolumn{4}{|c|}{ Duration of hormone replacement therapy use (months) } \\
\hline 0 & 96 & 125559 & 1.00 (referent) \\
\hline $1-11$ & 12 & 23210 & $0.66(0.36-1.20)$ \\
\hline $12-59$ & 26 & 20497 & $1.61(1.04-2.48)$ \\
\hline$>60$ & 33 & 10338 & $3.93(2.64-5.87)^{\star}$ \\
\hline
\end{tabular}

${ }^{*} P$ for trend $<0.05$ 
a relatively early age at menarche (data not shown). Women with higher glycaemic load values also consumed greater quantities of carbohydrates and sugars and glycaemic load values were strongly correlated with carbohydrate and sugar intake $(r=0.97$ and $r=0.79$, respectively). No appreciable variation was observed in mean energy intake, mean BMI, participation in vigorous physical activity, mean duration of HRT use or parity by quartile levels of glycaemic load. The patterns for overall glycaemic index were similar to those for the glycaemic load (data not shown).

Table 2 shows the associations between overall glycaemic index and glycaemic load and endometrial cancer risk. No association was found between glycaemic load and endometrial cancer risk in the age- and energyadjusted models. After additional adjustment for potential confounders, a $36 \%$ increased risk of endometrial cancer was observed for the highest versus the lowest quartile level of glycaemic load $(95 \% \mathrm{CI}=1.01-1.84 ; \quad P$ for trend $=0.21$ ). In age- and energy-adjusted models, risk of endometrial cancer was increased at all quartile levels of overall glycaemic index above the baseline category, although neither the increases in risk (which ranged from $10 \%$ to $34 \%$ ) nor the associated test for trend were statistically significant. After adjustment for additional potential confounding variables, the pattern was similar, but the increases in risk were slightly higher. Adjustment for total dietary fibre intake did not change the HR for either glycaemic load or overall glycaemic intake appreciably (data not shown). There was little variation in risk of endometrial cancer in association with total carbohydrate or total sugar intake (Table 2).

Table 3 shows the associations between quartiles of glycaemic index and glycaemic load and risk of endometrial cancer within strata defined by categories of BMI $\left(<25,25-29,>30 \mathrm{~kg} \mathrm{~m}^{-2}\right)$, participation in vigorous physical activity (none vs. some), menopausal status and use of HRT (never vs. ever). Among women in the two lower categories of BMI, glycaemic load was not associated with risk of endometrial cancer. In contrast, among obese women (BMI $>30 \mathrm{~kg} \mathrm{~m}^{-2}$ ), a statistically significant $88 \%$ increased risk was observed for the highest versus the lowest quartile level of glycaemic load $\left(\mathrm{g} \mathrm{day}^{-1}\right.$ ) although the associated test for trend was not statistically significant $(P$ for trend $=0.54$ ). Although a $47 \%$ increase in risk was observed between the highest compared with the lowest quartile level of overall glycaemic index among obese women, the increase in risk was not statistically significant and there was no evidence for a linear trend in risk. No statistically significant associations were observed

Table 2 Adjusted $^{*}$ hazard ratios (HR) and 95\% confidence intervals $(\mathrm{Cl})$ for the association between overall glycaemic index and glycaemic load and risk of endometrial cancer

\begin{tabular}{|c|c|c|c|}
\hline \multirow[b]{2}{*}{ Model } & \multirow[b]{2}{*}{ Cases/person-years } & \multicolumn{2}{|c|}{$\mathrm{HR}(95 \% \mathrm{Cl})$} \\
\hline & & Age- \& energy-adjusted & Multivariate-adjustec \\
\hline \multicolumn{4}{|c|}{ Glycaemic load $\left(\right.$ g day $\left.^{-1}\right)$} \\
\hline$<125$ & $95 / 142056$ & 1.00 (referent) & 1.00 (referent) \\
\hline $125-147$ & $113 / 141485$ & $0.90(0.90-1.56)$ & $1.27(0.95-1.69)$ \\
\hline $148-169$ & $106 / 141230$ & $0.83(0.83-1.45)$ & $1.23(0.92-1.66)$ \\
\hline$>169$ & $112 / 140438$ & $0.87(0.87-1.52)$ & $1.36(1.01-1.84)$ \\
\hline$P$ for trend & & 0.70 & 0.21 \\
\hline \multicolumn{4}{|c|}{ Overall glycaemic index } \\
\hline$<67$ & $108 / 141292$ & 1.00 (referent) & 1.00 (referent) \\
\hline $67-72$ & 105/141308 & $1.10(0.79-1.53)$ & $1.19(0.84-1.67)$ \\
\hline $73-77$ & $103 / 141275$ & $1.14(0.77-1.69)$ & $1.29(0.86-1.94)$ \\
\hline$>77$ & $110 / 141333$ & $1.34(0.84-2.15)$ & $1.47(0.90-2.41)$ \\
\hline$P$ for trend & & 0.33 & 0.14 \\
\hline \multicolumn{4}{|c|}{ Total carbohydrate $\left(\mathrm{g} \mathrm{day}^{-1}\right)$} \\
\hline$<179$ & $97 / 141764$ & 1.00 (referent) & 1.00 (referent) \\
\hline $179-204$ & $109 / 141586$ & $1.10(0.82-1.46)$ & $1.23(0.82-1.66)$ \\
\hline $205-227$ & $112 / 141440$ & $1.08(0.80-1.47)$ & $1.23(0.89-1.70)$ \\
\hline$>227$ & $108 / 140496$ & $1.01(0.69-1.48)$ & $1.19(0.80-1.78)$ \\
\hline$P$ for trend & & 0.87 & 0.32 \\
\hline \multicolumn{4}{|c|}{ Total sugar $\left(\mathrm{g} \mathrm{day}^{-1}\right)$} \\
\hline$<64$ & $93 / 141264$ & 1.00 (referent) & 1.00 (referent) \\
\hline $64-79$ & $112 / 141444$ & $1.18(0.89-1.55)$ & $1.23(0.92-1.63)$ \\
\hline $80-95$ & 104/141677 & $1.09(0.82-1.44)$ & $1.17(0.87-1.56)$ \\
\hline$>95$ & $117 / 140823$ & $1.18(0.90-1.56)$ & $1.26(0.94-1.68)$ \\
\hline$P$ for trend & & 0.26 & 0.10 \\
\hline
\end{tabular}

* Multivariable models included body mass index in $\mathrm{kg} \mathrm{m}^{-2}(<25,25-29,>30)$, menopausal status, smoking (pack-years), alcohol (quartiles), use of hormone replacement therapy (never plus three levels of duration), use of oral contraceptives (never plus three levels of duration), parity (quintiles), age at menarche ( $<12$ vs. $>12$ years of age), participation in vigorous physical activity (any/none/missing), intake of energy (as a continuous variable), study centre and treatment allocation. 


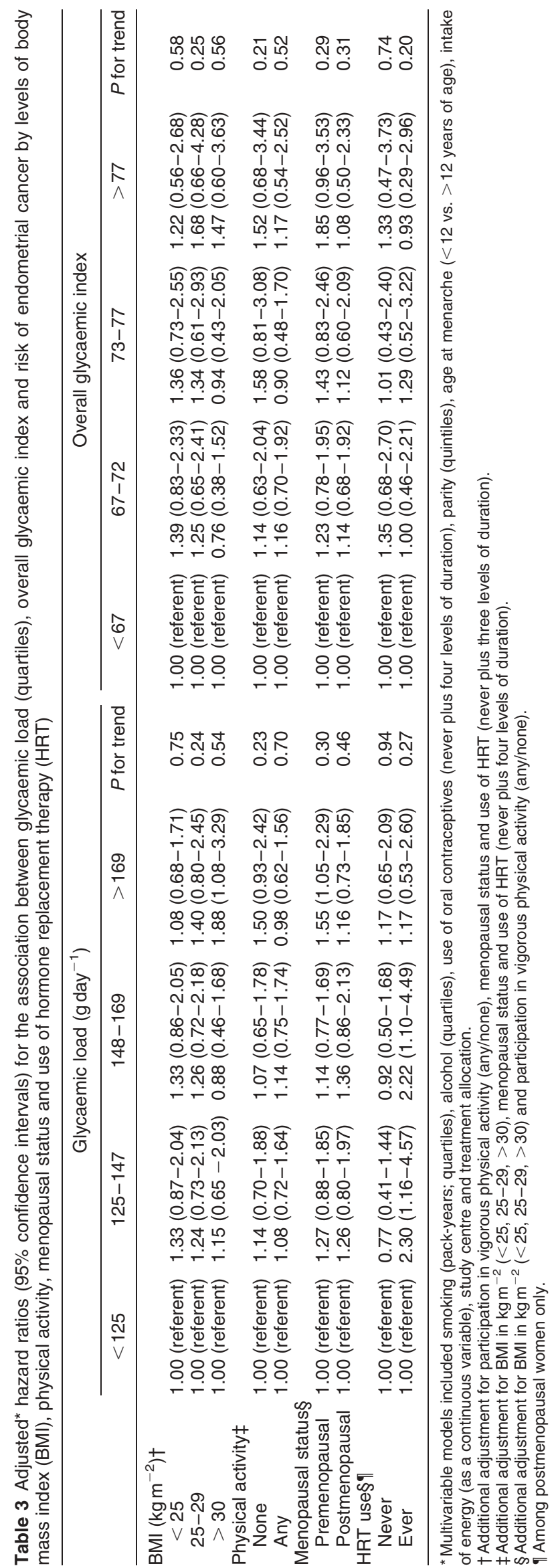


between overall glycaemic index and endometrial cancer risk among normal- and overweight women. Among women who did not participate in vigorous physical activity, there was some evidence of positive associations between overall glycaemic index and glycaemic load and endometrial cancer risk, while, in contrast, there were no associations between either overall glycaemic index or glycaemic load and endometrial cancer risk among women who did participate in vigorous physical activity (Table 3). Among women who were premenopausal at baseline the highest versus the lowest quartile level of overall glycaemic index was associated with an $85 \%$ increased risk of endometrial cancer $(95 \% \mathrm{CI}=0.96-3.53$; $P$ for trend $=0.29)$. Similarly, a statistically significant increased risk was observed among the highest versus lowest quartile level of glycaemic load ( $\mathrm{HR}=1.55$, 95\% $\mathrm{CI}=1.05-2.29 ; \quad P$ for trend $=0.30)$. Neither overall glycaemic index nor glycaemic load was associated with endometrial cancer risk among women who were postmenopausal at baseline. There was some evidence that risk of endometrial cancer associated with glycaemic load was higher among postmenopausal women who reported ever using HRT than among those who had never used HRT (Table 3). In contrast, we found no variation in risk across strata of HRT use for overall glycaemic index. On formal testing, there was evidence for effect modification of the association between glycaemic load and endometrial cancer risk by HRT use $\left(\chi^{2}(3)=12.03\right.$, $P=0.02)$, but not by BMI $\left(\chi^{2}(6)=9.03, P=0.17\right)$, menopausal status $\left(\chi^{2}(3)=6.16, P=0.10\right)$ or participation in vigorous physical activity $\left(\chi^{2}(3)=2.19\right.$, $P=0.53)$. There was no evidence for effect modification of the association between overall glycaemic index and endometrial cancer risk by BMI $\left(\chi^{2}(6)=8.48, P=0.20\right)$, physical activity $\left(\chi^{2}(3)=2.20, P=0.33\right)$, menopausal status $\left(\chi^{2}(3)=2.53, P=0.47\right)$ or HRT use $\left(\chi^{2}(3)=5.86\right.$, $P=0.12)$.

\section{Discussion}

The results of the prospective study reported here provide some support for positive associations between glycaemic load and overall glycaemic index and endometrial cancer risk. In contrast, no association was found between either total sugar or total carbohydrate intake and risk of endometrial cancer. The lack of an association with carbohydrate consumption is in keeping with a previous analysis of these data based on follow-up of the cohort to the end of 1993, by which time 221 cases had occurred ${ }^{27}$. An increase in risk of endometrial cancer was observed at the highest quartile level of glycaemic load among obese women. Given that high BMI is generally associated with increased fasting insulin ${ }^{28}$ and decreased insulin sensitivity $^{29-31}$, women who are obese may have a more pronounced insulin response to foods with higher glycaemic values.
Two previous studies have examined the relationship between glycaemic index/load and endometrial cancer. One, a hospital-based case-control study of 410 cases and 753 unmatched controls, reported a statistically significant increased risk for the highest versus the lowest quintile level of overall glycaemic index but did not find any association with glycaemic load ${ }^{14}$. The association with overall glycaemic index was found to be stronger among women aged 60 years and over, among women with BMI $>25 \mathrm{~kg} \mathrm{~m}^{-2}$ and among users of HRT ${ }^{14}$. The second study, based on data from the Iowa Women's Health (IWH) study cohort, included 415 incident endometrial cancer cases and did not find an association between overall glycaemic index and risk, but did report a borderline statistically significant trend of increasing risk with increasing dietary glycaemic $\operatorname{load}^{15}$. This association was found to be stronger among non-diabetic women than among diabetic women $^{15}$, and particularly among non-diabetic women who were obese or who were HRT users.

The latter study differed from ours in a number of ways. First, glycaemic load values were higher in the IWH study ${ }^{15}$ (quintile cut points in the IWH were 147, 163, 176 and 193 vs. $119,139,155$ and $175 \mathrm{~g} \mathrm{day}^{-1}$ in our study). It is possible, therefore, that an association between overall glycaemic index and/or glycaemic load and endometrial cancer risk exists at higher values only, and that the lack of an association in our study population was due to the lower glycaemic index/load values. Second, our study population included both pre- and postmenopausal women, whereas the study population examined by Folsom et al. ${ }^{15}$ was limited to postmenopausal women only. In contrast to Folsom et al., we found no association between glycaemic load and endometrial cancer risk among women who were postmenopausal at baseline, although we did observe a statistically significant increased risk of endometrial cancer associated with glycaemic load among women who were premenopausal at baseline. However, given that information on menopausal status in our study was collected at baseline only, that the minimum age at baseline was 40 years and that there was an average 16 years of follow-up, it is likely that most of those who were premenopausal at enrolment would have become postmenopausal during the course of follow-up. Thus it is likely that our results for premenopausal women are largely accounted for by a mix of endometrial cancers diagnosed pre- and postmenopausally.

Folsom et $a l .{ }^{15}$ reported a positive association between glycaemic load and the incidence of endometrial cancer among non-diabetic women, whereas a statistically nonsignificant inverse association was observed among women with diabetes (10\% of incident endometrial cancer cases reported having diabetes at baseline). Unlike Folsom et $a l .{ }^{15}$ we did not collect data on diabetes, and therefore were unable to adjust for it in the analysis. However, although there is evidence from epidemiological studies to support a causal association between diabetes mellitus 
and endometrial cancer ${ }^{32}$, it is not immediately obvious that failure to adjust for diabetes would have confounded the associations observed here. Specifically, in the 1980s dietary recommendations for diabetics stressed high intake of complex carbohydrates and fibre and low fat consumption $^{20,33}$. These recommendations were similar to those commonly promoted at that time for the population as a whole $e^{34}$. Hence, it is unlikely that there were any substantial differences in dietary patterns for diabetics and non-diabetics during the period in which dietary data were collected for the present study. Nevertheless, if those diagnosed with diabetes had altered their diet to (for example) include more foods with low glycaemic index values, then it is possible that our inability to adjust for diabetes could have obscured a positive association between glycaemic index/load and endometrial cancer risk.

Our data are further limited by the possibility of error with respect to the measurement of diet and the calculation of glycaemic load. Error in the measurement of daily intake of carbohydrates and sugars may have resulted from inaccurate recall ${ }^{35}$. Additionally, measurement error might have occurred due to the fact that the glycaemic index values of some foods are currently based on only one or two, often small, studies ${ }^{4}$. However, this applies to the previous studies of glycaemic index/load and endometrial cancer as well. It is also possible that some women may have undergone a hysterectomy during the follow-up, and if the rate of subsequent hysterectomy differed by levels of some risk factor, this would have introduced bias into the results. In addition, the results stratified by physical activity should be interpreted with caution given that approximately $22 \%$ of the study subjects were missing information on physical activity. Also, although we adjusted our estimates for a wide range of potentially confounding variables, uncontrolled confounding by dietary and other factors cannot be excluded. Furthermore, given the complex associations between glycaemic load and smoking history, alcohol consumption and oral contraceptive use in our study population, residual confounding may have contributed to our findings as well.

The main strengths of this investigation are its prospective study design, which eliminates the possibility of recall bias. As well, the essentially complete follow-up of the cohort ${ }^{36,37}$, based on linkage to national cancer incidence and mortality databases, reduces the likelihood that our results reflect bias due to differential follow-up.

In conclusion, our study suggests that dietary glycaemic load and overall glycaemic index may be associated with risk of endometrial cancer overall, and, in particular, that a relatively high dietary glycaemic load might be associated with increased risk among obese women and premenopausal women. Our findings also suggest that glycaemic load is positively associated with endometrial cancer risk among postmenopausal women who have used HRT. Given the lack of prospective data regarding glycaemic index and glycaemic load and endometrial cancer risk, additional cohort studies are needed to confirm these findings.

\section{Acknowledgements}

This work was funded in part by the National Cancer Institute of Canada. We thank Statistics Canada, the provincial and territorial Registrars of Vital Statistics, and the Cancer Registry directors for their assistance in making the cancer incidence and mortality data available.

\section{References}

1 Holt S, Miller JC, Petocz P. An insulin index of foods: the insulin demand generated by $1000-\mathrm{kJ}$ portions of common foods. American Journal of Clinical Nutrition 1997; 66: $1264-86$.

2 Ionescu-Tirgoviste C, Popa E, Sintu E, Mihalache N, Cheta D, Mincu I. Blood glucose and plasma insulin responses to various carbohydrates in type 2 (non-insulin-dependent diabetes). Diabetologia 1983; 24: 80-4.

3 Jenkins D, Kendall CW, Augustin LS, Franceschi S, Hamidi M, Marchie A, et al. Glycemic index: overview of implications in health and disease. American Journal of Clinical Nutrition 2002; 76: 266S-73S.

4 Foster-Powell K, Holt SH, Brand-Miller JC. International table of glycemic index and glycemic load values: 2002. American Journal of Clinical Nutrition 2002; 76: 5-56.

5 Brynes S, Miller JCB, Denyer GS. Amylopectin starch promotes the development of insulin resistance in rats. Journal of Nutrition 1995; 125: 1430-7.

6 Ludwig D. Dietary glycemic index and obesity. Journal of Nutrition 2000; 130: 280S-3S.

7 Plymate S, Jones RE, Matej LA, Friedl KE. Regulation of sex hormone binding globulin (SHBG) production in Hep G2 cells by insulin. Steroids 1988; 52: 339-40.

8 Preziosi P, Barrett-Connor E, Papoz L, Roger M, Saint-Paul M, Nahoul K, et al. Interrelation between plasma sex hormonebinding globulin and plasma insulin in healthy adult women: the Telecom study. Journal of Clinical Endocrinology and Metabolism 1993; 76: 283-7.

9 Kaaks R, Lukanova A, Kurzer MS. Obesity, endogenous hormones, and endometrial cancer risk: a synthetic review. Cancer Epidemiology, Biomarkers \& Prevention 2002; 11: $1531-43$.

10 Lukanova A, Zeleniuch-Jacquotte A, Lundin E, Micheli A, Arslan AA, Rinaldi S, et al. Prediagnostic levels of C-peptide, IGF-1, IGFBP-1, -2, and -3 and risk of endometrial cancer. International Journal of Cancer 2004; 108: 262-8.

11 Kaaks R, Lukanova A. Energy balance and cancer: the role of insulin and insulin-like growth factor-I. Proceedings of the Nutrition Society 2001; 60: 91-106.

12 Henderson B, Feigelson HS. Hormonal carcinogenesis. Carcinogensis 2000; 21: 427-33.

13 Deligdisch L. Hormonal pathology of the endometrium. Modern Pathology 2000; 13: 285-94.

14 Augustin L, Gallus S, Bosetti C, Levi F, Negri E, Franceschi S, et al. Glycemic index and glycemic load in endometrial cancer. International Journal of Cancer 2003; 105: 404-7.

15 Folsom AR, Demissie Z, Harnack L. Glycemic index, glycemic load, and incidence of endometrial cancer: The Iowa Women's Health Study. Nutrition and Cancer 2003; 46: $119-24$. 
16 Jenkins DJ, Wolever TM, Buckley G, Lam KY, Guidici S, Kalmusky J, et al. Low-glycemic-index starchy foods in the diabetic diet. American Journal of Clinical Nutrition 1988; 48: $248-54$.

17 Terry P, Miller AB, Rohan TE. Obesity and colorectal cancer risk in women. Gut 2002; 51: 191-4.

18 Miller AB, Baines CJ, To T, Wall C. Canadian National Breast Screening Study. I. Breast cancer detection and death rates among women aged $4-49$ years. II. Breast cancer detection and death rates among women aged 5-59 years. Canadian Medical Association Journal 1992; 147: 1459-88.

19 Jain M, Harrison L, Howe GR, Miller AB. Evaluation of a selfadministered dietary questionnaire for use in a cohort study. American Journal of Clinical Nutrition 1982; 36: 931-5.

20 Morgan $\mathrm{AB}$, Jain $\mathrm{M}$, Miller $\mathrm{AB}$, Choi NW, Matthews V, Munan L, et al. A comparison of dietary methods in epidemiologic studies. American Journal of Epidemiology 1978; 107: 488-98.

21 Liu S, Manson JE, Stampfer MJ, Holmes MD, Hu FB, Hankinson SE, et al. Dietary glycemic load assessed by foodfrequency questionnaire in relation to plasma high-densitylipoprotein cholesterol and fasting plasma triacylglycerols in postmenopausal women. American Journal of Clinical Nutrition 2001; 73: 560-6.

22 Terry PD, Jain M, Miller AB, Rohan TE. Glycemic load, carbohydrate intake, and risk of colorectal cancer in women: a prospective cohort study. Journal of the National Cancer Institute 2003; 95: 914-6.

23 Willett W, Stampfer MJ. Total energy intake: implications for epidemiologic analyses. American Journal of Epidemiology 1986; 124: 17-27.

24 Rothman KJ, Greenland S. Modern Epidemiology, 2nd ed. Philadelphia, PA: Lipincott-Raven, 1998; 319.

25 Jain M, Miller AB. Tumor characteristics and survival of breast cancer patients in relation to premorbid diet and body size. Breast Cancer Research and Treatment 1997; 42: 43-55.

26 Rohan TE, Hartwick W, Miller AB, Kandel RA. Immunohistochemical detection of c-erbB- 2 and $\mathrm{p}-53$ in benign breast disease and breast cancer risk. Journal of the National Cancer Institute 1998; 90: 1262-9.

27 Jain M, Rohan TE, Howe GR, Miller AB. A cohort study of nutritional factors and endometrial cancer. European Journal of Epidemiology 2000; 16: 899-905.

28 Kaaks RLA. Effects of weight control and physical activity in cancer prevention: role endogenous hormone metabolism. Annals of the New York Academy of Sciences 2002; 963 : 268-81.

29 Kelley DGB. Effects of physical activity on insulin action and glucose tolerance in obesity. Medicine and Science in Sports and Exercise 1999; 31: 619S-23S.

30 Giovannucci E. Insulin, insulin-like growth factors and colon cancer: a review of the evidence. Journal of Nutrition 2001; 131: 3109S-20S.

31 Borghouts LKH. Exercise and insulin insensitivity: a review. International Journal of Sports Medicine 2000; 21: 1-12.

32 Persson I, Adami HO. Endometrial cancer. In: Adami HO, Hunter D, Trichopoulos D, eds. Textbook of Cancer Epidemiology. Oxford: Oxford University Press, 2002; 359-77.

33 American Diabetes Association. Principles of nutrition and dietary recommendations for individuals with diabetes mellitus. Diabetes 1979; 28: 1027.

34 Statement on nutrition and your health: dietary guidelines for Americans. Journal of the American Dietetic Association 1986; 86: 107-8.

35 Willett W. Nutritional Epidemiology. New York: Oxford University Press, 1998.

36 Robles SC, Marrett LD, Clarke EA, Risch EA. An application of capture-recapture methods to the estimation of completeness of cancer registration. Journal of Clinical Epidemiology 1988; 41: 495-501.

37 Shannon HS, Jamieson E, Walsh C, Julian JA, Fair ME, Buffet A. Comparison of individual follow-up and computerized record linkage using the Canadian Mortality Data Base. Canadian Journal of Public Health 1989; 80: 54-7. 